\title{
Application of sensitivity analysis in DYMOND/Dakota to fuel cycle transition scenarios
}

\author{
S. Richards* and B. Feng \\ Argonne National Laboratory, Lemont, United States
}

Received: 15 July 2021 / Received in final form: 29 July 2021 / Accepted: 18 November 2021

\begin{abstract}
The ability to perform sensitivity analysis has been enabled for the nuclear fuel cycle simulator DYMOND through its coupling with the design and analysis toolkit Dakota. To test and demonstrate these new capabilities, a transition scenario and multi-parameter study were devised. The transition scenario represents a partial transition from the US nuclear fleet to a closed fuel cycle with small modular LWRs and fast reactors fueled by reprocessed used nuclear fuel. Four uncertain parameters in this transition were studied - start date of reprocessing, total reprocessing capacity, the nuclear energy demand growth, and the rate at which the fast reactors are deployed - with respect to their impact on four response metrics. The responses - total natural uranium consumed, maximum annual enrichment capacity required, total disposed mass, and total cost of the nuclear fuel cycle - were chosen based on measures known to be of interest in transition scenarios [2] and to be significantly impacted by the varying parameters. Analysis of this study was performed both from the direct sampling and through surrogate models developed in Dakota to calculate the global sensitivity measures Sobol' indices. This example application of this new capability showed that the most consequential parameter to most metrics was the share of new build capacity that is fast reactors. However, for the cost metric, the scaling factor of the energy demand growth was significant and had synergistic behavior with the fast reactor new build share.
\end{abstract}

\section{Introduction}

The nuclear fuel cycle is a complicated system with many feedback mechanisms that can have unintuitive effects when transitioning between fuel cycles. Successfully analyzing a potential change in a fuel cycle, either due to policy or emergence of a new technology, requires a nuclear fuel cycle simulator (NFCS). However, NFCSs require many free parameters to allow the flexibility to model the large range of potential fuel cycles and facilities, with many of these parameters being left to the judgement of the user as there have been no real-world equivalents of the potential reactors or facilities described. This freedom also creates parametric uncertainties - uncertainty that is the result of the assumptions of the parameter's values. To better understand the models that are being simulated and the results of these uncertainties, sensitivity analysis and uncertainty quantification (SA\&UQ) is incorporated into the NFCS calculations [1]. How system performance changes in response to changes of uncertain parameters is studied through sampling methods and surrogate models. These are used to calculate a distribution

\footnotetext{
* e-mail: srichards@anl.gov
}

on system performance measures and to understand which parameters, or parameter synergistic relationships, contribute most to their variance. To perform this analysis, a framework based on Design Analysis Kit for Optimization and Terascale Application (DAKOTA) was developed and interfaced with the NFCS DYMOND. DYMOND allows for accurate representation of the dynamic changes in nuclear fuel compositions through its coupling with ORIGEN for depletion calculations and direct critical fuel composition calculations. This analysis framework was applied to an example nuclear fuel cycle transition scenario to reveal both the parametric and the synergistic effects between four free parameters and four response metrics of significance. The free parameters in this study were chosen based on experience of the limiting factors in the transition from the current U.S. once-through nuclear fuel cycle to a closed cycle with reprocessing: when reprocessing starts, the annual reprocessing capacity, the growth of energy demand, and the rate at which advanced fast reactors are deployed. The response metrics were chosen to be in line with several of the evaluation criteria chosen for the U.S. Nuclear Fuel Cycle Evaluation and Screening Report [2] - natural uranium required, annual enrichment capacity required, mass of nuclear waste that requires disposal, and the levelized (in $2020 \mathrm{US} \$$ ) cost of 
the fuel cycle transition as estimated based on data from the Advanced Fuel Cycle Cost Basis Report [3].

\section{Modeling capabilities}

\subsection{DYMOND}

DYMOND [4] is a NFCS developed and maintained by Argonne National Laboratory. The code models the nuclear fuel cycle through hybrid modeling paradigms, combining system dynamics, discrete event, and agentbased modeling using the AnyLogic modeling platform and depletion physics through coupling with ORIGEN2. The work flow of DYMOND uses these different paradigms to manage the abstraction level of the nuclear fuel cycle. Material flows, transport, and head-end processes are modeled as stocks and flows within a system with feedback mechanisms dictated by the higher definition agents. Agent models are used for the reactors and reprocessing with discrete event models dictating their construction, operational state, and decommissioning. The model is organized in this manner to mirror the level of granularity needed when studying potential benefits of technologies or policies on hypothetical fuel cycles. The preserved component linking the model abstraction levels is the composition of the materials at key locations in the fuel cycle - at reactor facilities in the core, in spent fuel storage, at reprocessing plants, in separated storage, in storage awaiting disposal, and in final disposal. DYMOND explicitly tracks 25 nuclides actinides that have the greatest impact on fuel recycling in advanced reactor concepts - and currently a lumped material composite of all fission products. The transmutation of nuclear fuel in a reactor is calculated using pre-generated reactor-specific depletion libraries in ORIGEN2. These calculations determine the fuel composition after irradiation and cooling from a reactor based on the reactor power and cycle specifications. Decay of materials in all parts of the fuel cycle is also accounted for through a simplified Bateman equation solver for the explicitly tracked nuclides that recalculates material compositions at each month of the simulation. The coupling of ORIGEN also allows for a more advanced feature - determination of fresh fuel composition requirements through a criticality search - as an alternative to the commonly used fuel "recipes" or approximate nuclide reactivity worth (i.e., Pu239 equivalence). This feature more accurately determines fuel requirements from reprocessed material streams for a wider range of reactor designs with material-stream composition feedback mechanisms and minimal approximations. Though the use of these more physically accurate modeling capabilities is more computationally expensive, DYMOND has been made compatible with both concurrent execution and multiple-processor parallelism to off-set the computational cost.

\subsection{Dakota}

Dakota [5] is a standardized toolkit developed by Sandia National Laboratory for optimization, global sensitivity and variance analysis, parameter estimation, uncertainty quantification, and verification. Dakota is designed as an ease-of-use tool for interfacing optimization and analysis methods with a wide range of engineering software under otherwise difficult conditions. These difficult problems include those that adopt meta-level strategies such as surrogate models and hybrid-optimization or multi-level parallelism. It is thanks to this design that advanced modeling techniques can be used in this study to overcome difficulties that arise in NFCS such as computationally expensive simulations that include both time-dependent system evolution and evolution of the fuel compositions through depletion, decay, and other physics. The DYMOND/Dakota application in this study was performed through direct sampling and the use of surrogate models (a quadratic regression and Gaussian process model) trained on the massive amount of data generated from the direct sampling of DYMOND. Dakota is publicly released and available through Sandia at dakota.sandia.gov. The main classes of problems that Dakota is designed to solve are parameter studies, design and analysis of computer experiments (DACE), uncertainty quantification, optimization, and calibration. This effort makes use of parameter studies via joint variation on a multidimensional grid to generate global sensitivity measures using Monte Carlo sampling methods (Latin Hypercube Sampling). The goal is to use sensitivity analysis techniques to identify which of the design parameters have the most influence on the response quantities. This information is useful as both an assessment of the behavior of response functions as well as a preliminary step in the optimization of a model by limiting the parameter space that needs to be explored. For this work, Sobol' indices from the parameteric study were chosen from the available measures for sensitivity analysis in Dakota. Sobol' indices provide a global, as opposed to local, measure of the importance of parameters. There are other options for measuring global sensitivity in Dakota, however, Sobol' indices provide a greater quantification of synergistic effects. The Dakota interface allows these tools to be applied to DYMOND, and a coupling of the two codes to be developed. In Dakota, an interface is what defines a function evaluation or response creation but is otherwise considered a black-box. The DYMOND/Dakota coupling scheme developed in this work has Dakota act as the driver, generating the parameter inputs and managing either the serial or parallel execution of the interface, whether that be the DYMOND model or a data-generated surrogate model. The interface that was created to allow Dakota to interact with DYMOND makes use of the Dakota interfacing Python module and a DYMOND-native distributed file system. The Python module simplifies the interaction with Dakota parameter and result files by managing the construction and syntax, and the DYMOND-native file system allows for data preservation and simulation modularity. These two features allow for the study to be quickly and easily repeated in case of changes in response evaluations or simulation/calculation errors that require restarting or repeating. 
Table 1. Design and operational specifications for all reactors modeled in the study.

\begin{tabular}{|c|c|c|c|c|}
\hline & PWR & BWR & SMR & GFR \\
\hline Reactor power (MWe) & 1007.00 & 1044.38 & 300.00 & 1100.00 \\
\hline Capacity factor & 0.92 & 0.93 & 0.92 & 0.89 \\
\hline Thermal efficiency & 0.35 & 0.34 & 0.31 & 0.5 \\
\hline $\begin{array}{l}\text { Equilibrium burnup } \\
\text { (GWd/MTHM) }\end{array}$ & 50.00 & 45.00 & 37.30 & 49.80 \\
\hline Number of batches & 3 & 3 & 3 & 3 \\
\hline Cycle length (EFPD) & 493 & 682 & 672 & 481 \\
\hline Operational lifetime & 60 & 60 & 60 & 60 \\
\hline $\begin{array}{l}\text { Annual fuel } \\
\text { requirement } \\
\text { (MTHM/yr) }\end{array}$ & 19.35 & 23.29 & 8.64 & 14.35 \\
\hline Core size (MTHM) & 85.24 & 139.79 & 51.89 & 63.75 \\
\hline $\begin{array}{l}\text { Average fresh fuel } \\
\text { enrichment }\end{array}$ & $4.54 \%$ & $4.18 \%$ & $4.54 \%$ & $\mathrm{~N} / \mathrm{A}$ \\
\hline
\end{tabular}

\section{Partial fuel cycle transition sensitivity analysis study}

\subsection{Scenario description: fuel cycle transition to SMRs and GFRs}

The fuel cycle transition scenario that is the basis of the study is a transition from the current U.S. nuclear fuel cycle to a fuel cycle consisting of small modular light water reactors (SMRs) and fast-spectrum reactors designed to operate in an actinide burning, rather than breeding, regime. For demonstration purposes only, the fast reactor technology chosen for this study is the gas-cooled fast reactor (GFR) since extensive studies have already been performed using DYMOND on transitioning to the sodium and molten-salt cooled fast reactor technologies. Since the SMRs are LWRs that operate in once-through mode with LEU, it is still technically part of the initial fuel cycle, hence this can be considered a "partial" transition.

This partial transition is set to begin in 2020 with spent fuel being stored for reprocessing starting in 2020, reprocessing beginning in 2035, advanced reactors first being deployed in 2040, and the simulation terminating in 2100 . The scenario begins with the current U.S. nuclear fleet consisting of legacy pressurized water reactors (PWR) and boiling water reactors (BWR) where each is modeled using the average power, capacity factor, fuel enrichment, fuel batch reload mass, effective full power days per cycles, number of in-core cycles per batch, final burnup, and thermodynamic efficiency of reactors of currently operating of the same type (Tab. 1). These reactors are also modeled to have the average operational lifetime of 60 years with reactor start dates being back-calculated such that shutdowns are in-line with currently announced plans for shutdown or approved license extensions as of February, 2020 [6].

Deployment of announced and under construction reactor projects as of January 2020 (AP-1000s Vogtle reactor 3 and 4 planned for start-up in 2021 and 2022 as well as NuScale-UAMPs SMR installation planned for start-up in 2027) were also included and modeled as Gen-III PWRs with design and operating specifications matching those reported for the NuScale SMR [7]; the much larger AP1000 reactors were approximated as an installment of 4 of these reactors. These Gen-III SMRs are deployed to meet projected nuclear energy demand (Fig. 1) until advanced reactors can begin to be deployed in 2040. The fast reactors are based on a modified design of the GFR-2400 [8,9] where the fuel stream has been allowed to have a greater concentration of transuranics, and the operation of the reactor reaches a higher average final burnup by extending the cycle length. The deployment of the GFRs is designed as a gradual market intrusion, linearly increasing to meet a $40 \%$ share of new-build reactor-capacity, calculated on a 5-year moving average, at the end of the simulation in 2100.

The deployment schedule for all reactors after 2027 (the last year that a new reactor is currently planned to startup) is calculated to meet the projected nuclear energy demand [10], following the guidelines of which reactors are able to be deployed, with the smallest excess of additional capacity possible. The caveat to those guidelines, though, is that the first GFR is required to be started in 2040 regardless of demand, and that all reactors must operate at their listed capacity factor for the entirety of their operating lifetime. This results in overproduction of energy in 2048-2051 (see Fig. 2), equivalent to multiple SMRs' capacities due to a predicted sharp decline in demand that greatly exceeds the rate of loss of capacity from reactors shutting down. However, outside of these years, the deployment schedule closely matches the demand, with excess capacities of less than one SMR-equivalent, while also closely following a linear increase in advanced reactor deployment rate. At the end of the simulation, this ramping of advanced reactor deployment culminates in GFRs being $31.2 \%$ of nuclear energy generating capacity (Fig. 1).

While the LWRs in the study are refueled using enriched uranium oxide fuel, the advanced reactors in the study are fueled primarily from reprocessed fuel streams containing uranium, plutonium, and all other minor actinides. No enrichment of the reprocessed material is performed, instead the fuel composition is found using DYMOND's 


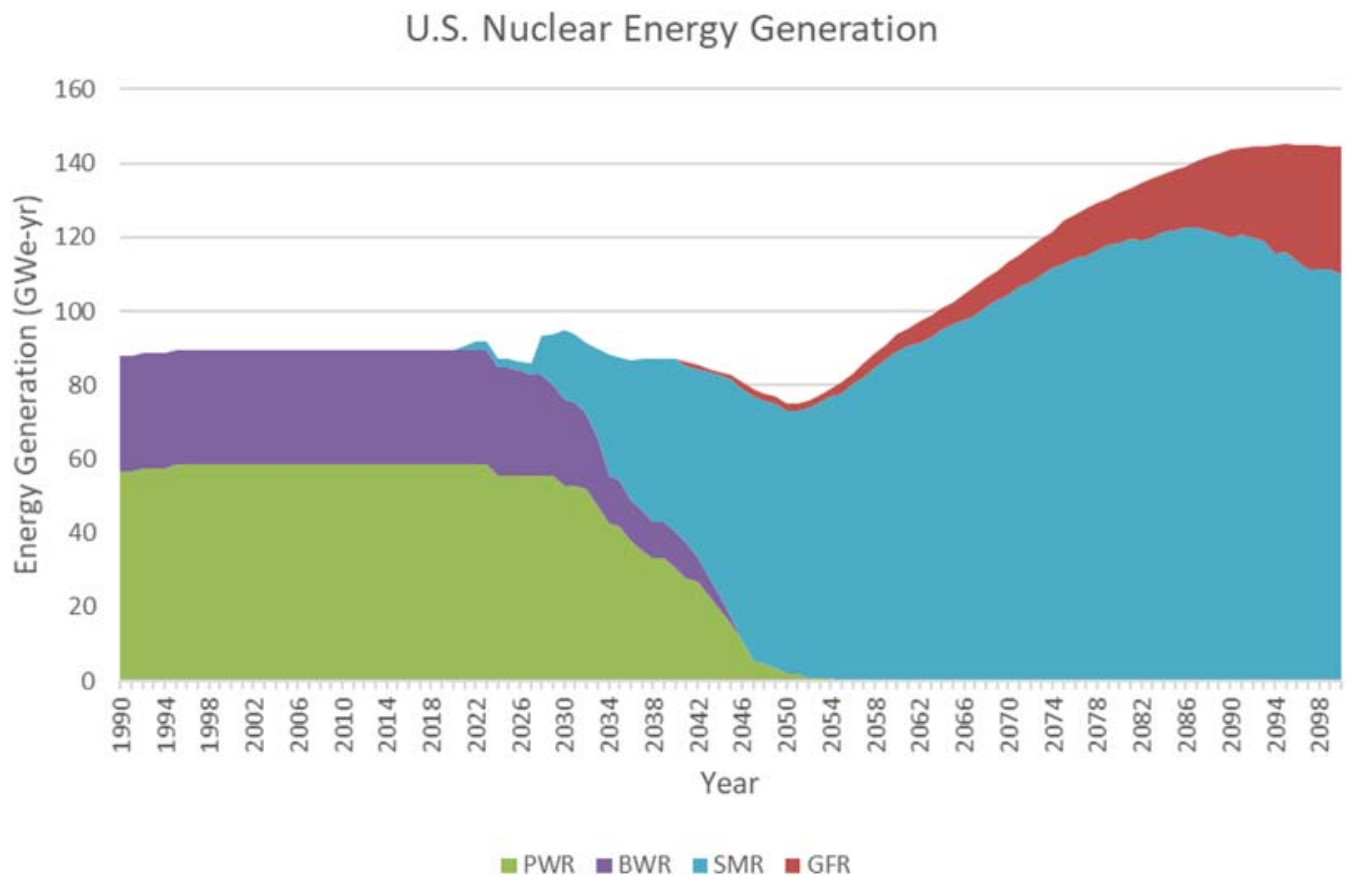

Fig. 1. Base scenario energy production by reactor type.

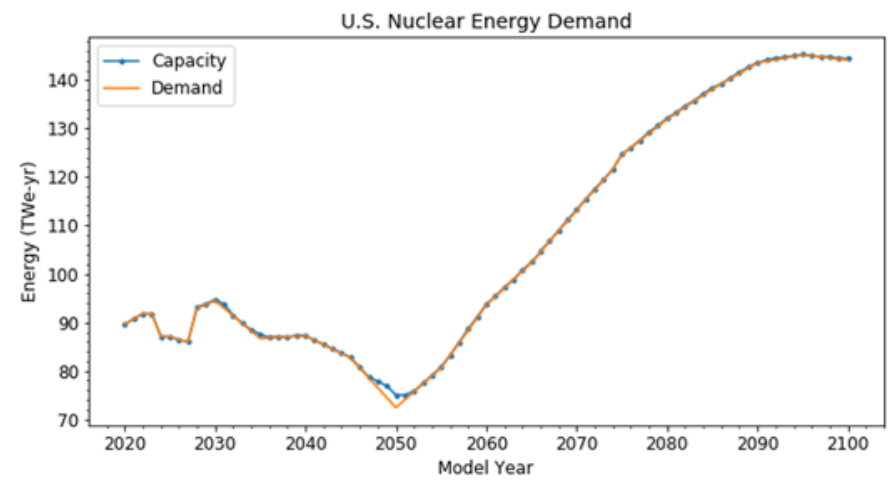

Fig. 2. Base scenario U.S. nuclear energy demand and total generating capacity.

criticality search functionality. This calculates a fabrication ratio of reprocessed material to a make-up material (in the case of this study, either depleted uranium from the enrichment process or natural uranium, which is considered sufficiently plentiful) for each fuel batch requested by a reactor. The reprocessed material streams are differentiated by their reactor of origin, and which of the material streams is used for fuel fabrication is dictated by the defined source priority of the reactor requesting the fuel. The GFR design in the study prioritizes fuel sources in the order of SMR, legacy PWR, legacy BWR, and finally GFR with unlimited recycle. This priority was chosen based on the reactivity worth of the reprocessed spent fuel from each of the source reactors, prioritizing the material stream that required the minimal actinide content to achieve end-of-cycle criticality. The available material for advanced reactor fuel fabrication can be seen in Figure 3, which shows that there is no significant stock

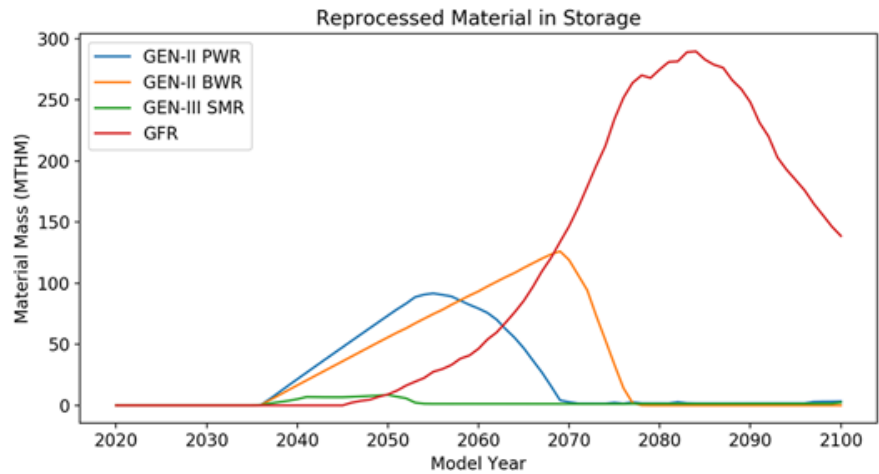

Fig. 3. Reprocessed material available for use in GFR fuel fabrication by reactor of material origin.

of SMR origin material and the stocks of legacy reactor reprocessed materials are fully depleted by 2070 and 2078 for the PWR and BWR origin material, respectively. The stock of reprocessed GFR material reaches a maximum of 289.67 tonnes in 2084. This is also the date with the greatest total amount of reprocessed material in storage (292.79 tonnes).

The reprocessing facilities for this study are modeled as bulk processes where only one facility of each type exists and the plant capacity is fixed for the entirety of the fuel cycle. There are two types of reprocessing processes modeled: an aqueous process based on Purex facilities but with no separation of uranium or plutonium from the minor actinides, and a pyroprocessing process. Both types are modeled to be batch processes (i.e., no mixing or distribution of residency times) with $0.1 \%$ losses and a process time of 1 year. However, the aqueous reprocessing requires the used fuel to be cooled for 5 years post discharge and 
the pyroprocessing only requires 2 years of cooling before reprocessing. The two methods of reprocessing are used to account for the different characteristics and operational knowledge in reprocessing of the used fuel streams. Aqueous reprocessing is used for the LWR used fuel due to the existing facilities using aqueous reprocessing methods and the demonstrated high capacity of these facilities to reprocess LWR fuel. Pyroprocessing was chosen for the GFR used fuel stream due to the higher flexibility of the process to allow for various fuel forms, higher temperatures of the fuel, and fabrication of radioactive fuel.

In the preliminary work to develop the base scenario, the capacity of the aqueous reprocessing was the main determinant of whether there was a fuel shortage and the pyroprocessing capacity determined the peak mass of reprocessed material in storage. This is due to the priorities given to the fuel streams. The reprocessing of the LWR fuel must be high enough to keep up with the fuel requirements for the deployment of the GFRs, with startup cores requiring the most total mass. The reprocessing of the GFR fuel must build up a sufficient stockpile so that once the GEN-II LWRs' fuel has been used there is enough to support the new reactor deployment until the end of the simulation. The minimum capacities then are correlated, as a lower capacity to reprocess the LWR fuel results in less being available for starting up GFRs early in the simulation, so a higher reprocessing capacity for the GFR fuel is required to meet demand. However, this would also result in the stock of LWR fuel from prior to the start of the first GFR lasting longer. The minimum combined capacity, with no fuel shortages, if reprocessing begins in 2035 is found to be approximately $1000 \mathrm{MTHM} /$ year. In order for the base scenario to be more representative of an "average" scenario, rather than one on the periphery of the parameter space for the study, the total capacity was set at $1500 \mathrm{MTHM} /$ year. This capacity was divided amongst the two types of reprocessing: $1200 \mathrm{MTHM} /$ year for the aqueous process and $300 \mathrm{MTHM} /$ year for pyroprocessing.

\subsection{Study parameters}

Four variables of the fuel cycle transition were chosen as the parameters for this study -

1. The start date of the reprocessing facilities (RPS) - This parameter controls the year that both reprocessing facilities would begin operation and ranged between the beginning of the simulation (2020) and the startup date of the first advanced reactor (2040) with both facilities modeled as having the same startup date. In the sampling of this parameter, only integer values were allowed - as that is the modeling restriction placed on the variable by DYMOND. However, when using surrogate models for the calculation, RPS is considered continuous.

2. The annual reprocessing capacity (RPC) for the reprocessing facilities - This parameter controls annual capacity for each of the reprocessing types, where both types are given the same capacity. The capacities for both aqueous and pyroprocessing were set as equal to reduce the number of parameters and because of the negligible impact that varying the pyroprocessing plant capacity has on the responses chosen for this study. This parameter ranges between $500 \mathrm{MTHM} / \mathrm{yr} /$ facility and $3000 \mathrm{MTHM} / \mathrm{yr} /$ facility, putting the entirety of the study safely in the regime of the used advanced reactor fuel production rate being the limiting factor.

3. A scaling factor for the year-to-year growth of nuclear energy demand (GSF) - This parameter scales the energy demand increase, or decrease, between years based on the change in the base case scenario. However, the demand prior to 2027 does not change, as those years are considered constant and set by current data rather than projections. The range of GSF is from 0 to 4 , where any factor less than 1 would be a decrease in the demand growth and a factor of 0 would be a constant demand.

4. The advanced reactor share of new-build reactorcapacity at the end of the simulation (NBS) - This parameter not only effects the build rate of advanced reactors at the end of the simulation but also the build rate of advanced reactors during the transition as the new build share of advanced reactors is calculated to scale linearly from the first deployment in 2040 up to NBS in 2100. This parameter ranged from a $10 \%$ final share (0.1) to $50 \%$ (0.5). Anything less than $10 \%$ would result in very few GFRs being constructed, and a share of greater than $50 \%$ would result in too many scenarios having fuel shortages.

The sampling of these parameters was ensured to be evenly distributed across the ranges through Dakota's Latin Hypercube sampling (LHS), as can be seen in the distribution of sampling points in Figure 4. The sampling of 2400 scenarios was uniformly distributed for all parameters with the lower quartile, median, and upper quartile values equally dividing the range between the extreme values. The results of this sampling, with failed scenarios removed, were used in the training of the surrogate models, with the number of samples chosen based on the guidance in the Dakota user's manual. The suggested minimum number of samples for variance decomposition studies is:

$$
100 * P *(R+2)
$$

where $P$ is the number of parameters being sampled and $R$ is the number of responses being generated from the parameter set. This minimum is to ensure sufficient coverage of the parameter space and a high statistical significance of response variance. In the reduced parameter space sampling, this same number of samples is used, however, when using the surrogate models the number of samples is increased to 10,000 as the computational cost for increasing the number of samples is insignificant - on the order of seconds of computational time.

\subsection{Response evaluation}

The purpose of the study is to quantify the sensitivity of four response metrics: total mass of natural uranium 

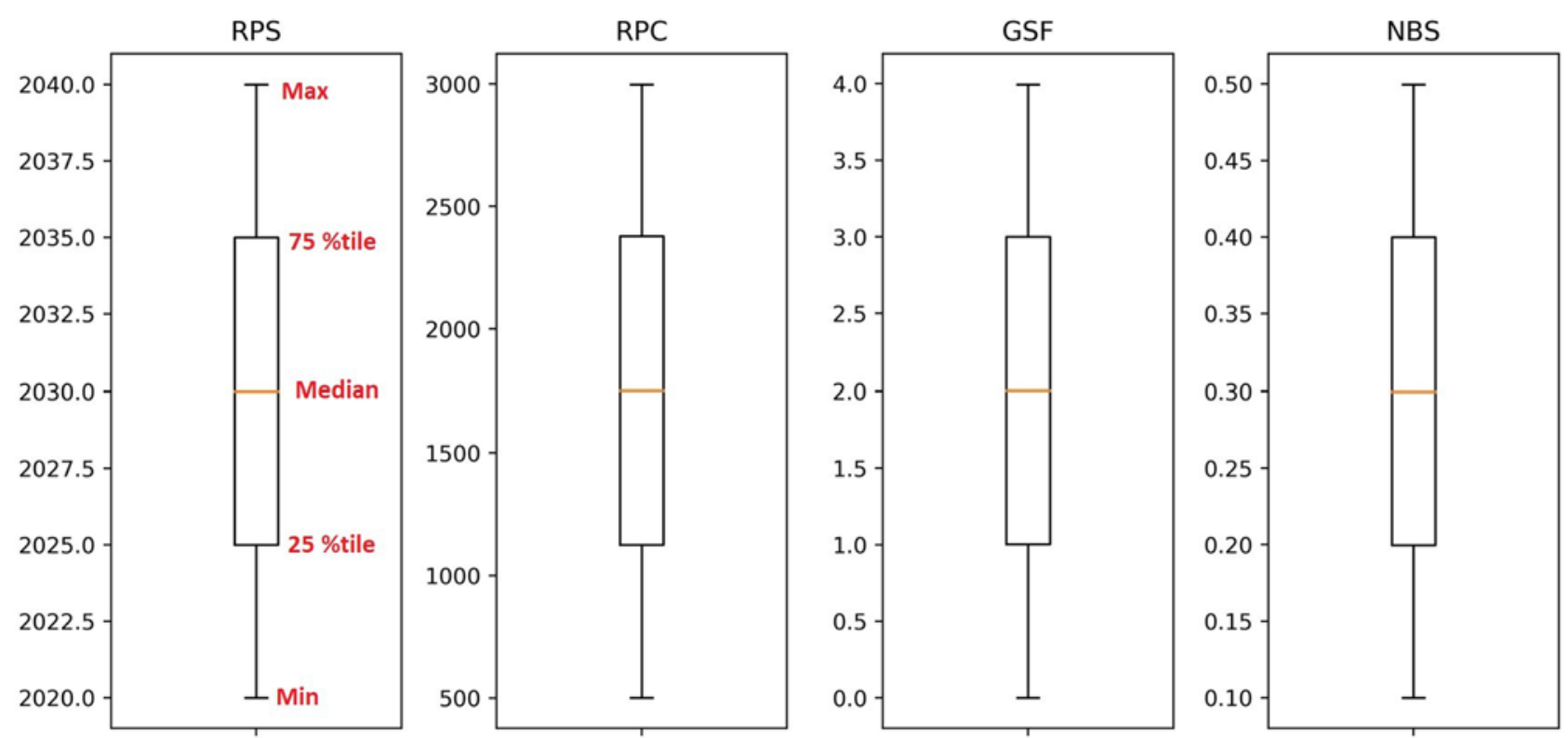

Fig. 4. Distribution of the 2400 samples by parameter.

consumed in (MTU/GWe-yr), maximum annual enrichment capacity required (Tonne SWU/GWe-yr), mass of nuclear waste that requires disposal (MTHM/GWe-yr), and the levelized (in 2020 US\$/GWe-yr) cost of the fuel cycle transition with component costs estimated based on the Advanced Fuel Cycle Cost Basis Report [3]. These four response metrics were chosen to closely resemble several of the criteria used in the U.S. Nuclear Fuel Cycle Evaluation and Screening Report [2]. The four response metrics were calculated from values in DYMONDs output - a database record of annual stocks, flows, compositions, and state points at critical points in the fuel cycle and normalized to the total energy produced in the scenario.

The calculations for each metric is explained below:

1. total mass of natural uranium consumed per energy produced - This response is calculated as the difference in the stock of natural uranium at the beginning of the simulation and the end of the simulation divided by the summation of energy produced in each year. This method is used, as opposed to tracking all outflows of natural uranium to the enrichment facility and as make-up material in fuel fabrication, because DYMOND does not consider mining activities and as such there is no material stream that can increase the initial stock of natural uranium.

2. Maximum annual enrichment capacity required per energy produced - DYMOND does not explicitly place a limit on the annual reprocessing capacity in the model, it is instead set a priori to be whatever is required to meet the enrichment needs of the fuel fabrication for that given year. Therefore, the Tonne-SWU enrichment capacity is calculated from the material flows and compositions of the natural uranium, depleted uranium, and enriched uranium through the enrichment facility by:

$$
\begin{aligned}
& \qquad W_{S W U}=P * V\left(x_{p}\right)+T * V\left(x_{T}\right)-F * V\left(x_{F}\right) \\
& \text { where, } \quad V(x)=1-2 x * \ln \left(\frac{1-x}{x}\right) \\
& \text { and, } \quad F=P+T .
\end{aligned}
$$

In these equations $P$ is the mass of enriched uranium produced, $T$ is the mass of depleted uranium produced, $F$ is the mass of natural uranium required to produce masses $P$ and $T$, and $x$ is the respective enrichments of the material corresponding to the subscript. This value is tracked for each reactor independently at each year in a scenario, with the response using the maximum annual total across all reactors normalized to the total energy produced in the transition.

3. Mass of nuclear waste that requires disposal per energy produced - All materials in the simulation that are not being stored as a stock for another potential use (e.g., used fuel that will be reprocessed, depleted uranium that can be used as make-up material in fuel fabrication, etc.) will be directed to final disposal and are considered nuclear waste. However, DYMOND tracks all sources and material streams separately. In other words, each reactor type will have two contributing material streams - spent fuel directly from the reactor, and high-level waste that is from the reprocessing facility with that reactor-type of origin. This allows for waste streams to be differentiated, but in the case of this response metric all materials are assumed to be equal. This assumption allows for the total mass disposed to be calculated as the difference in mass in disposal at the start of the simulation and at the end of the simulation, with the addition of the mass of material that is "waiting for disposal" due to cooling time 
Table 2. Fuel cycle costs from table S-1 in 2017 cost basis report [3].

\begin{tabular}{|c|c|c|c|c|}
\hline Component & CBR module & Units & $2017 \$$ & $2020 \$$ \\
\hline $\begin{array}{l}\text { Natural Uranium Mining and } \\
\text { Milling }\end{array}$ & A1 & $\$ / \mathrm{kgU}$ & 86 & 89.44 \\
\hline Conversion Process & B & $\$ / \mathrm{kgU}$ & 13 & 13.52 \\
\hline Enrichment & $\mathrm{C} 1$ & $\$ / \mathrm{kg}-\mathrm{SWU}$ & 125 & 130 \\
\hline $\begin{array}{l}\text { LEU Fuel Fabrication (PWR } \\
\text { UO }_{2} \text { ) }\end{array}$ & D1-1 & $\$ / \mathrm{kgHM}$ & 400 & 416 \\
\hline $\begin{array}{l}\text { LEU Fuel Fabrication (BWR } \\
\text { UO }_{2} \text { ) }\end{array}$ & D1-1 & $\$ / \mathrm{kgHM}$ & 400 & 416 \\
\hline $\begin{array}{l}\text { Remote handled fuel fabrication } \\
\text { from reprocessed material }\end{array}$ & $\mathrm{D} 2 / \mathrm{F} 2$ & $\$ / \mathrm{kgHM}$ & 1400 & 1456 \\
\hline $\begin{array}{l}\text { COEX Total Aqueous } \\
\text { reprocessing of UOX fuel }\end{array}$ & F1 & $\$ / \mathrm{kgHM}$ & 1562 & 1624.48 \\
\hline $\begin{array}{l}\text { Electrochemical and remote } \\
\text { handling fuel recycle }\end{array}$ & $\mathrm{D} 2 / \mathrm{F} 2$ & $\$ / \mathrm{kgHM}$ & 1200 & 1248 \\
\hline $\begin{array}{l}\text { Co-located storage of reprocessed } \\
\text { transuranic fuel material }\end{array}$ & E3-1B & $\$ / \mathrm{kgTRU}$ & 950 & 988 \\
\hline LWR Construction & R1 & $\$ / \mathrm{kWe}$ & 4400 & 4576 \\
\hline LWR O\&M Fixed Component & $\mathrm{R} 1$ & $\$ /$ kWe-yr & 73 & 75.92 \\
\hline LWR O\&M Variable Component & R1 & $\$ / \mathrm{kWh}$ & 0.0018 & 0.001872 \\
\hline Fast Reactor Construction & $\mathrm{R} 2$ & $\$ / \mathrm{kWe}$ & 4100 & 4264 \\
\hline $\begin{array}{l}\text { Fast Reactor O\&M Fixed } \\
\text { Component }\end{array}$ & $\mathrm{R} 2$ & $\$ /$ kWe-yr & 76 & 79.04 \\
\hline $\begin{array}{l}\text { Fast Reactor O\&M Variable } \\
\text { Component }\end{array}$ & $\mathrm{R} 2$ & $\$ / \mathrm{kWh}$ & 0.0022 & 0.002288 \\
\hline $\begin{array}{l}\text { Aqueous reprocessing derived } \\
\text { HLW conditioning, storage, and } \\
\text { packaging }\end{array}$ & G1-1A & $\$ / \mathrm{kg}$ & 5700 & 5928 \\
\hline $\begin{array}{l}\text { Electrochemical reprocessing } \\
\text { derived HLW conditioning, } \\
\text { storage, and packaging }\end{array}$ & G1-2A & $\$ / \mathrm{kg}$ & 17214 & 17902.56 \\
\hline $\begin{array}{l}\text { Spent fuel conditioning, storage, } \\
\text { and packaging }\end{array}$ & G2 & $\$ / \mathrm{kg}$ & 135 & 140.4 \\
\hline $\begin{array}{l}\text { Geological Repository for spent } \\
\text { fuel }\end{array}$ & L1 & $\$ / \mathrm{kg}$ & 600 & 624 \\
\hline Geological Repository for HLW & L1 & $\$ / \mathrm{kg}$ & 6000 & 6240 \\
\hline
\end{tabular}

restrictions. If material is in storage at any other point in the model at the end of simulation, then it will not be included in this response.

4. Levelized cost of the nuclear fuel cycle during transition - The calculation of the levelized cost of the transition is the most complicated, accounting for 20 separate factors in the fuel cycle. The factors that are listed in Table 2 are taken from table S-1 in the 2017 cost basis report (CBR) [3]. These factors, and the assumptions made in calculating them, are given in more description in the CBR modules listed in Table 2. Further assumptions that were made in applying the costs in the CBR modules to the DYMOND model are:

- COEX Total Aqueous reprocessing of UOX fuel is assumed to match the process needed for the reprocessing of the LWR used fuel due to the product stream being the closest match to that desired for the FR design.

- The cost of fuel reprocessing using pyro-processing can be applied through the same steps as the aqueous reprocessing. The cost is based on studies that were available at the time of the evaluation and extrapolated costs based on the difference in the e-chem process and the UREX process.

- Co-located storage costs are only calculated for cask storage, with other storage methods to be considered included with the cost of the associated facility.

- Fast Reactor construction and O\&M costs estimated based on experience with sodium fast reactor extrapolated to Nth of a kind scale deployment of large reactors. Over the course of the simulation, this is assumed to be a sufficiently accurate representation of this cost. With hundreds of reactors being built, the first-of-a-kind costs won't significantly impact the overall fuel cycle cost.

- Costs for final geological disposal of spent nuclear fuel and HLW are only calculated for material that reaches that stage of the simulation by the final simulated year. Any material in other storages in the 
model (such as fuel waiting to be reprocessed) is not included in this cost.

The costs in Table 2 are being applied to either direct values from the DYMOND model, or values that have to be derived from other values due to the construction and material management of the model. These values, how they are represented in the output, and how costs are applied to them are described going from the head end of the fuel cycle through to final disposal, and all output masses are in units of tonnes:

- the mining, milling, and conversion costs are all applied at the same time and are calculated based on the sum of the natural uranium, enriched uranium, and enrichment tails flows. This value is in the output labeled as "Mined ore".

- The enrichment costs are relative to the annual required $\mathrm{kg}-\mathrm{SWU}$. This is calculated in the DYMOND model for all reactor types separately and is output as "SWU required".

- The fuel fabrication costs are calculated for all LWRs together (PWR, BWR, and SMR) and the FR independently. The FR is assumed to be the Nth reactor type in the implementation and all other types are assumed to be LWRs. This assumption is also true for all other costs that are unique to reactor type such as reprocessing, HLW storage, and construction and operating costs. The reprocessing costs are assessed upon the material entering the reprocessing facility and is in the output as "SNF reprocessed".

- The cost of construction is assessed at the end of the first year that the NPP is operational is scaled based on plant capacity. A new NPP coming on line is described as "New Capacity" in the output as opposed to the "Installed capacity" of reactors that were already operational.

- O\&M costs are assessed at the end of the year and scaled by the amount of power that the NPP produced during that year. The reactors' power for the year is output as "Produced electricity" and is given in units MWe. This power is scaled to account for capacity factor, and unless there is a fuel shortage, is therefore accounting for refueling outages.

- The cost of SNF storage is assessed at the time that the fuel goes to the reprocessing facility or is sent to interim storage. The amount that enters these storages is not directly modeled in DYMOND but are instead calculated as the change in the stock of spent fuel at the two locations plus the amount that was removed. For the fuel at the reprocessing facility the values in the output of the stock are labeled as "Spent fuel waiting for RP", and the output flows is equal to what is going into the reprocessing plants. The storage facility inventory is labeled in the output as "Spent fuel in storage" and the flow leaving storage is "Spent fuel readying for disposal". Both of these are assessed in the same storage costs.

- The HLW going into storage is directly modeled in DYMOND and is labeled in the output as "HLW to storage".
- The disposal costs of the spent fuel and the high level waste are both calculated directly as those amounts of each being disposed are given in the output as "Spent fuel being disposed" and "HLW being disposed" respectively. Both of these values are treated as a gross sum with no origin or age distinction being made.

\subsection{Fuel cycle transition "failure" determination}

In the study, a fuel cycle transition scenario is considered to have failed if at any point in the simulation an insufficient amount of energy is generated to meet the demand. With the generation capacity of the fleet and reactor deployments strictly calculated to exceed the demand, this failure state can only be reached if an otherwise operational reactor is not generating power. In the current DYMOND model, this state can only be reached through a fuel shortage. Furthermore, the state can only be reached by a shortage in the primary fuel fabrication material feed from reprocessed used nuclear fuel due to the enrichment capacity at any given time step being equal to the required capacity to meet demand. This then means that fuel shortages, and therefore scenario failures, can only occur for reactors that are defined to take fuel fabricated from reprocessed material and no other source. The advanced reactors in this study meet that definition.

A scenario failure is defined as such so that it does not skew the sensitivity analysis results. Since all response quantities are power specific, the decreased generation during a fuel shortage could lead to adverse effects that over-emphasize, or are counter to, the local sensitivity of those parameters. Also, in the case that the results of a sensitivity analysis study are used for optimization, or to inform decisions, these failures could lead to undesired outcomes such as the quantity of material going to final disposal being minimized through reactor shutdowns due to fuel shortages.

In global sensitivity analysis, failures result in meaningless solutions. This is due to the sensitivity calculation relying on matching sets of samples with identical parameter values in one dimension to be able to measure the influence of the other parameters independent of that dimension. One method for resolving this issue is limiting the parametric space of the study. Assuming that the failures are constrained to the extreme values of one or more of the parameters, as is the case for this study, this solution will provide an accurate global measure of the sensitivity of the reduced region without introducing any new assumptions or biases. However, if there were successful scenarios in the removed parameter space, they will no longer have influence over the results as potential solutions. As mentioned in Section 2.2, the other solution for the issue of failed scenarios is the creation, and sampling, of surrogate models for determining global sensitivity measures. Dakota offers many surrogate modeling methods including polynomial regression, Gaussian process, and machine learning. In this study, a quadratic regression model and Gaussian process model are created from the successful transition scenarios from the 2400 samples of full parameter space described in Section 3.2. 

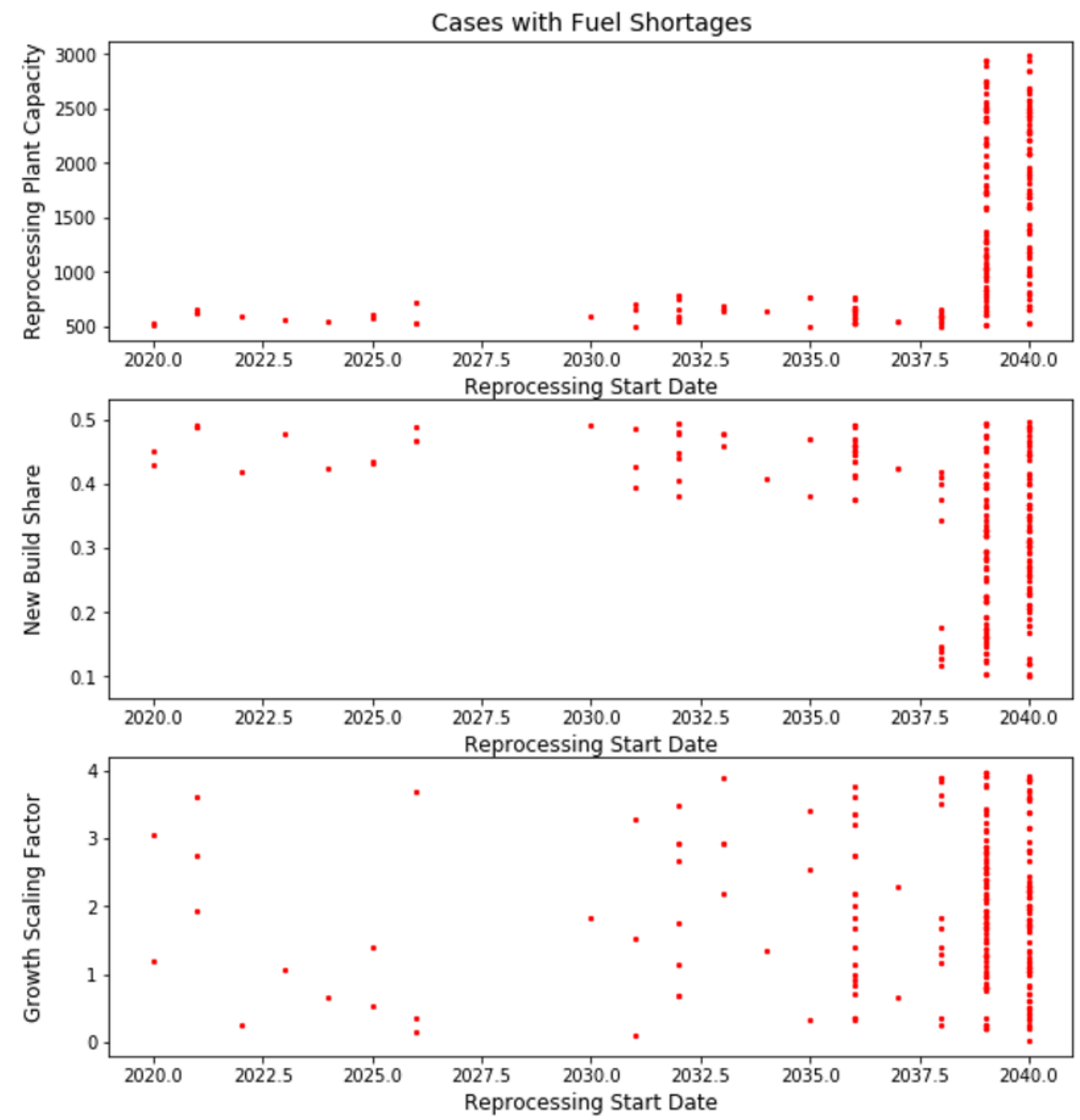

Fig. 5. Parameters of scenarios that resulted in a fuel shortage.

Calculating sensitivities from these surrogate models precludes the potential of failures while being able to sample the full range of potential parameter values. However, this also introduces a bias by being able to sample regions in the parameter space that do not meet the requirements of the transition scenario.

\section{Results}

\section{1 "Failure" space}

In deterministic models, the ranges of parameter values, or combinations of parameter values, that can result in a "failure" will define a region referred to as a "failure" space. In the case of this study, the parameters that most control whether a transition scenario will have a fuel shortage, and therefore be counted as a failure, are the reprocessing start date (RPS), the reprocessing capacity (RPC), and the share of new builds that are GFR advanced reactors (NBS). RPC and NBS have a strong synergistic effect on fuel shortages, as a function of those two parameters defines one edge of the failure space. It is likely, given the results of the sensitivity analysis, the energy demand growth (GSF) also has a synergistic effect with NBS and RPC to cause fuel shortages. However, either this effect is secondary to that of RPC and NBS, or the sampling region of the study does not contain that edge of the failure space.

RPS defines a hard cut-off - a single parameter defined edge of the failure space - for successful transitions. As can be seen in Figure 5, any time to start reprocessing after 2038 results in fuel shortages. This is from the characteristics of the reprocessing plants and fuel fabrication process - both have a process time of 1 year. If the first reprocessing plant begins operation in 2039, regardless of its capacity, no fuel can be ready for the first GFR to startup at the start of 2040. This relationship therefore is obvious at the reprocessing capacities studied, resulting in 202 of the 259 failed scencarios (out of 2400 total scenarios sampled from 600 independent point). However, if either the initial deployment of advanced reactors were higher, 


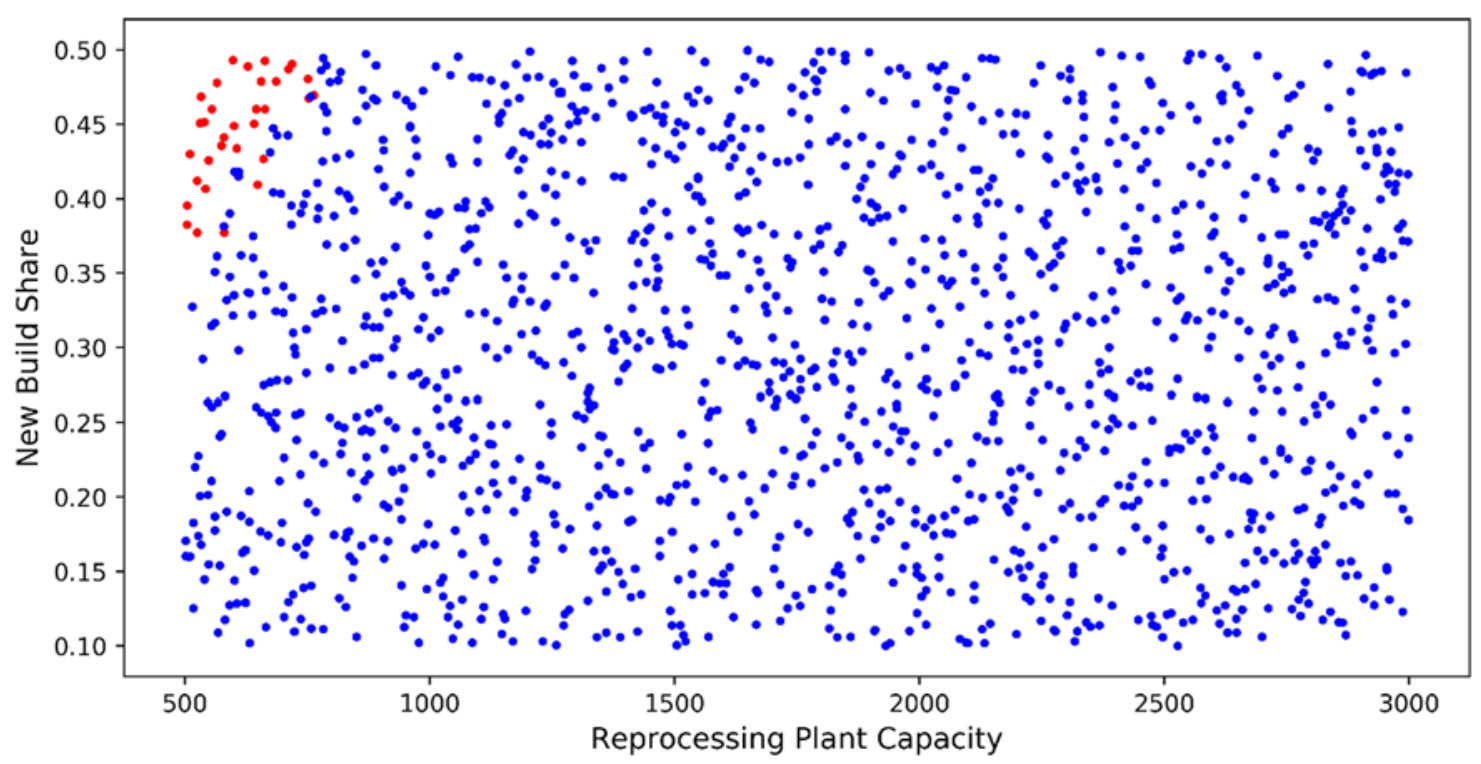

Fig. 6. The sample space of reprocessing capacity for each of the two plant types and the advanced reactor new build share at the end of the simulation. (RED - fuel shortage, BLUE - successful transition.)

or if the reprocessing capacity in the fuel cycle were very low, it is expected that this direct relationship would be synergistic with the other parameters. This would be a result of multiple years of accumulation of reprocessed material being needed to meet the demand of the larger startup fuel loading. In order to remove this failure pathway from the limited region sampling, RPS was limited to the range of 2020-2038. The other primary contributor to fuel shortages, responsible for the other 57 failed scenarios, is the relationship between NBS and RPC. Fuel shortages arose at some point in the transition for cases with a high NBS and a low RPC. These shortages are more difficult to predict as they come at later times in the scenario. Figure 6 illustrates how the relationship between the two parameters define one edge of the failure space. The slight overlap of the successes and failures in the figure is due to it being a two dimensional projection and, as stated earlier, GSF has a slight influence on this failure type at this boundary point. Due to this boundary being curved, it is more difficult to account for in the reduced sampling space study. Rather than trying to match the curve of the boundary, RPC was limited to the range of $785 \mathrm{MTHM} / \mathrm{yr}$ to $3000 \mathrm{MTHM} / \mathrm{yr}$. This effectively sets the reprocessing capacity high enough so that there will be sufficient material at even the highest deployment rate of GFRs in the study.

Through this "Failure" space study, it was possible to determine quantitatively two decisions that needed to be made to remove all fuel shortage scenarios given the assumptions: start reprocessing between 2020 and 2038 and keep the reprocessing capacity above $785 \mathrm{MTHM} / \mathrm{yr}$.

\subsection{Sobol' indices}

Sobol' indices give a measure of the contribution of each parameter to the variance observed in a response metric.
In the case of DACE with deterministic models, the variance is the same as the range of values of the output that are possible given a range of values of the inputs, i.e., the importance of a parameter to a response metric. There are two measures provided by Sobol' indices, the main effect index and the total effect index. The main effect index indicates the fraction of the variance that a parameter is solely responsible for. This is measured by the ratio of variance that is observed in the response metric at each point that the parameter is constant, averaged over all other parameters, to the total variance in the response. The total effect index is a measure fraction of the main effect of the parameter and all synergistic effects that parameter has with the other parameters [5]. In this context, a synergistic effect may be a constructive or destructive interaction of any order between two or more parameters that results in the behavior of the response metric not being purely additive from the main effects of the constituent parameters. The total effect is measured as the ratio of the average variance in the response, when only the parameter being measured is allowed to vary, to the total variance in the response. This measurement is akin to a quantification of the average behavior that would be observed from doing many parametric studies on the parameter being measured at different sets of values of the other parameters. These measures of importance are tabulated for the three methods of removing failures in Tables 3-5. The negative numbers reported in these tables are a numerical artifact resultant from the method used in Dakota to calculate these values, signifying that the value is below precision for the calculation given the number of samples (approximately 0.01 for the limited parameter space sampling and 0.004 for the surrogate model samplings).

While the three failure elimination methods agree on the main contributors for each response metric, the difference in magnitudes of these importances indicates that 
Table 3. Main effect indices and total effect indices for the limited parameter space sampling.

\begin{tabular}{|c|c|c|c|}
\hline Response Metric & Parameter & $\mathbf{S}_{i}$ - Main Effect & $\mathbf{S}_{T O T}$ - Total Effect \\
\hline \multirow{4}{*}{$\begin{array}{c}\text { Natural Uranium } \\
\text { Consumed per Energy } \\
\text { Produced }\end{array}$} & $\begin{array}{l}\text { Reprocessing Capacity } \\
\text { (RPC) }\end{array}$ & $0.00 \mathrm{E}+00$ & $0.00 \mathrm{E}+00$ \\
\hline & $\begin{array}{l}\text { Energy Demand } \\
\text { Growth Scaling } \\
\text { (GSF) }\end{array}$ & $4.05 \mathrm{E}-02$ & $1.90 \mathrm{E}-02$ \\
\hline & $\begin{array}{l}\text { AR New Build Share } \\
\text { (NBS) }\end{array}$ & $9.37 \mathrm{E}-01$ & $9.16 \mathrm{E}-01$ \\
\hline & $\begin{array}{l}\text { Reprocessing Start } \\
\text { Date (RPS) }\end{array}$ & $0.00 \mathrm{E}+00$ & $0.00 \mathrm{E}+00$ \\
\hline \multirow{4}{*}{$\begin{array}{c}\text { Normalized Maximum } \\
\text { Reprocessing Capacity } \\
\text { Required }\end{array}$} & $\begin{array}{l}\text { Reprocessing Capacity } \\
\text { (RPC) }\end{array}$ & $0.00 \mathrm{E}+00$ & $0.00 \mathrm{E}+00$ \\
\hline & $\begin{array}{l}\text { Energy Demand } \\
\text { Growth Scaling } \\
\text { (GSF) }\end{array}$ & $2.00 \mathrm{E}-02$ & $3.90 \mathrm{E}-02$ \\
\hline & $\begin{array}{l}\text { AR New Build Share } \\
\text { (NBS) }\end{array}$ & $8.92 \mathrm{E}-01$ & 8.70E-01 \\
\hline & $\begin{array}{l}\text { Reprocessing Start } \\
\text { Date (RPS) }\end{array}$ & $0.00 \mathrm{E}+00$ & $0.00 \mathrm{E}+00$ \\
\hline \multirow{4}{*}{$\begin{array}{c}\text { Mass of Waste } \\
\text { Disposed per Energy } \\
\text { Produced }\end{array}$} & $\begin{array}{l}\text { Reprocessing Capacity } \\
\text { (RPC) }\end{array}$ & $1.80 \mathrm{E}-01$ & $1.28 \mathrm{E}-01$ \\
\hline & $\begin{array}{l}\text { Energy Demand } \\
\text { Growth Scaling } \\
\text { (GSF) }\end{array}$ & $2.38 \mathrm{E}-02$ & $1.29 \mathrm{E}-02$ \\
\hline & $\begin{array}{l}\text { AR New Build Share } \\
\text { (NBS) }\end{array}$ & $8.46 \mathrm{E}-01$ & $7.66 \mathrm{E}-01$ \\
\hline & $\begin{array}{l}\text { Reprocessing Start } \\
\text { Date (RPS) }\end{array}$ & $-7.07 \mathrm{E}-03$ & $8.80 \mathrm{E}-04$ \\
\hline \multirow{4}{*}{$\begin{array}{l}\text { Levelized Cost of Fuel } \\
\text { Cycle Transition }\end{array}$} & $\begin{array}{l}\text { Reprocessing Capacity } \\
\text { (RPC) }\end{array}$ & $5.83 \mathrm{E}-03$ & $3.86 \mathrm{E}-03$ \\
\hline & $\begin{array}{l}\text { Energy Demand } \\
\text { Growth Scaling } \\
\text { (GSF) }\end{array}$ & $4.86 \mathrm{E}-01$ & $8.31 \mathrm{E}-01$ \\
\hline & $\begin{array}{l}\text { AR New Build Share } \\
\text { (NBS) }\end{array}$ & $3.74 \mathrm{E}-01$ & $4.68 \mathrm{E}-01$ \\
\hline & $\begin{array}{l}\text { Reprocessing Start } \\
\text { Date (RPS) }\end{array}$ & $2.40 \mathrm{E}-03$ & $1.57 \mathrm{E}-03$ \\
\hline
\end{tabular}

the removed range of values in the limited parameter space has a significant effect on the total variance and the distribution of the variance. Upon further inspection, it is found that though the mean response values for the reduced parameter space sampling are very similar to the full sampling, with no mean being more than $0.1 \%$ different, the variances are significantly smaller for all responses. The least changed variance is that of the waste disposed metric which is $95.3 \%$ of the true variance, but the rest of the variances are more than $10 \%$ lower with the cost metric variance being only $68.0 \%$. This means that the limited parameter space is not exactly representative of the larger space and the effects observed are nonlinear and non-additive. In particular, the importance of the NBS doubles from the total parameter space, as measured by the surrogate models, to the limited parameter space for the cost of the transition. This would indicate that much of the impact of the demand growth scaling factor on cost comes from scenarios with low reprocessing capacities. This is also seen in the other metrics, however, those effects are not as pronounced. Unlike the reduced parameter space study, the surrogate models, having been trained on the original sampling of the full parameter space, show good coverage of the responses. Neither surrogate model has a mean response value that deviates more than $0.1 \%$ from the training set or a response variance that is more than $4.5 \%$ different to that observed in the training set. However, the Gaussian process surrogate model provides a better fit to the data and will be considered as the proper measures of the global sensitivity for this study and all values discussed will be taken from Table 5 .

The four response metrics each have only one or two variance contributing parameters. Though all four parameters are given measured index values and the surrogate models have result precision, an index of less than 0.01 is in effect statistical noise as it is two orders of magnitude 
Table 4. Main effect indices and total effect indices for the quadratic regression surrogate model.

\begin{tabular}{|c|c|c|c|c|}
\hline Response Metric & Model Fit $\mathbf{R}^{2}$ & Parameter & $\mathbf{S}_{i}$ - Main Effect & $\mathbf{S}_{T O T}$ - Total Effect \\
\hline \multirow{4}{*}{$\begin{array}{c}\text { Natural Uranium } \\
\text { Consumed per Energy } \\
\text { Produced }\end{array}$} & \multirow{4}{*}{0.989} & $\begin{array}{l}\text { Reprocessing Capacity } \\
\text { (RPC) }\end{array}$ & $5.33 \mathrm{E}-04$ & $5.67 \mathrm{E}-05$ \\
\hline & & $\begin{array}{l}\text { Energy Demand } \\
\text { Growth Scaling } \\
\text { (GSF) }\end{array}$ & $1.04 \mathrm{E}-03$ & $4.27 \mathrm{E}-03$ \\
\hline & & $\begin{array}{l}\text { AR New Build Share } \\
\text { (NBS) }\end{array}$ & $9.72 \mathrm{E}-01$ & $9.74 \mathrm{E}-01$ \\
\hline & & $\begin{array}{l}\text { Reprocessing Start } \\
\text { Date (RPS) }\end{array}$ & $-5.24 \mathrm{E}-05$ & $3.62 \mathrm{E}-05$ \\
\hline \multirow{4}{*}{$\begin{array}{c}\text { Normalized Maximum } \\
\text { Reprocessing Capacity } \\
\text { Required }\end{array}$} & \multirow{4}{*}{0.970} & $\begin{array}{l}\text { Reprocessing Capacity } \\
\text { (RPC) }\end{array}$ & $3.38 \mathrm{E}-05$ & $5.19 \mathrm{E}-05$ \\
\hline & & $\begin{array}{l}\text { Energy Demand } \\
\text { Growth Scaling } \\
\text { (GSF) }\end{array}$ & $5.51 \mathrm{E}-04$ & $3.42 \mathrm{E}-03$ \\
\hline & & $\begin{array}{l}\text { AR New Build Share } \\
\text { (NBS) }\end{array}$ & $9.72 \mathrm{E}-01$ & $9.75 \mathrm{E}-01$ \\
\hline & & $\begin{array}{l}\text { Reprocessing Start } \\
\text { Date (RPS) }\end{array}$ & $-2.60 \mathrm{E}-05$ & $9.99 \mathrm{E}-05$ \\
\hline \multirow{4}{*}{$\begin{array}{c}\text { Mass of Waste } \\
\text { Disposed per Energy } \\
\text { Produced }\end{array}$} & \multirow{4}{*}{0.989} & $\begin{array}{l}\text { Reprocessing Capacity } \\
\text { (RPC) }\end{array}$ & $2.05 \mathrm{E}-01$ & $2.36 \mathrm{E}-01$ \\
\hline & & $\begin{array}{l}\text { Energy Demand } \\
\text { Growth Scaling } \\
\text { (GSF) }\end{array}$ & $-1.86 \mathrm{E}-04$ & $1.99 \mathrm{E}-03$ \\
\hline & & $\begin{array}{l}\text { AR New Build Share } \\
\text { (NBS) }\end{array}$ & $7.49 \mathrm{E}-01$ & 7.47E-01 \\
\hline & & $\begin{array}{l}\text { Reprocessing Start } \\
\text { Date (RPS) }\end{array}$ & $6.49 \mathrm{E}-04$ & $1.58 \mathrm{E}-03$ \\
\hline \multirow{4}{*}{$\begin{array}{l}\text { Levelized Cost of Fuel } \\
\text { Cycle Transition }\end{array}$} & \multirow{4}{*}{0.800} & $\begin{array}{l}\text { Reprocessing Capacity } \\
\text { (RPC) }\end{array}$ & 7.30E-03 & $1.09 \mathrm{E}-02$ \\
\hline & & $\begin{array}{l}\text { Energy Demand } \\
\text { Growth Scaling } \\
\text { (GSF) }\end{array}$ & $7.98 \mathrm{E}-01$ & $7.84 \mathrm{E}-01$ \\
\hline & & $\begin{array}{l}\text { AR New Build Share } \\
\text { (NBS) }\end{array}$ & $1.83 \mathrm{E}-01$ & $1.94 \mathrm{E}-01$ \\
\hline & & $\begin{array}{l}\text { Reprocessing Start } \\
\text { Date (RPS) }\end{array}$ & $-1.43 \mathrm{E}-03$ & $1.73 \mathrm{E}-03$ \\
\hline
\end{tabular}

smaller than the primary contributors and bordering on the precision possible from the surrogate model in this case. The primary contributing parameter for three of the four response metrics ( $97 \%$ to natural uranium consumption, $95 \%$ to enrichment capacity needed, and $75 \%$ to mass of waste disposed) is NBS, which also is one the two contributors of the final response. The primary contributor of the final response metric ( $76 \%$ to total cost of the transition) is the demand growth scaling factor, GSF.

The share of advanced reactors deployed directly, and strongly, impacts the first two parameters due to the increase in advanced reactors eliminating the deployment of many LWRs which drive the need for natural uranium and enrichment. The effect on waste disposed is also direct in that more of the material being reprocessed in the fuel cycle originates from LWRs at low NBS, which generates more high level waste (HLW) as a byproduct of reprocessing. Reprocessing capacity is a secondary contributor to mass of waste disposed, with a positive trend indicating an increase in reprocessing capacity results in a greater quantity of waste produced, however this is a result of the model setup. After the start of stockpiling a reactor type's used fuel for reprocessing, it only contributes to waste as HLW coming from reprocessing. Due to this - and that for most scenarios there is a surplus of LWR UNF waiting to be reprocessed - the aqueous reprocessing capacity was the limiting factor in the quantity of HLW produced. Similarly, the effect of NBS on the total cost of the transition is not intuitive because the overall cost of the advanced reactors and the associated facilities are more expensive but an increase in the new build share of advanced reactors reduces the transition cost. The cost of fabricating fuel and operating an advanced reactor is 
Table 5. Main effect indices and total effect indices for the Gaussian process surrogate model.

\begin{tabular}{|c|c|c|c|c|}
\hline Response Metric & Model Fit $\mathbf{R}^{2}$ & Parameter & $\mathbf{S}_{i}$ - Main Effect & $\mathbf{S}_{T O T}$ - Total Effect \\
\hline \multirow{4}{*}{$\begin{array}{c}\text { Natural Uranium } \\
\text { Consumed per Energy } \\
\text { Produced }\end{array}$} & \multirow{4}{*}{1.0} & $\begin{array}{l}\text { Reprocessing Capacity } \\
\text { (RPC) }\end{array}$ & $-3.21 \mathrm{E}-04$ & $1.45 \mathrm{E}-03$ \\
\hline & & $\begin{array}{l}\text { Energy Demand } \\
\text { Growth Scaling } \\
\text { (GSF) }\end{array}$ & $-1.08 \mathrm{E}-03$ & $6.26 \mathrm{E}-03$ \\
\hline & & $\begin{array}{l}\text { AR New Build Share } \\
\text { (NBS) }\end{array}$ & $9.68 \mathrm{E}-01$ & $9.72 \mathrm{E}-01$ \\
\hline & & $\begin{array}{l}\text { Reprocessing Start } \\
\text { Date (RPS) }\end{array}$ & $1.08 \mathrm{E}-03$ & $4.22 \mathrm{E}-04$ \\
\hline \multirow{4}{*}{$\begin{array}{c}\text { Normalized Maximum } \\
\text { Reprocessing Capacity } \\
\text { Required }\end{array}$} & \multirow{4}{*}{1.0} & $\begin{array}{l}\text { Reprocessing Capacity } \\
\text { (RPC) }\end{array}$ & 4.11E-04 & 7.03E-03 \\
\hline & & $\begin{array}{l}\text { Energy Demand } \\
\text { Growth Scaling } \\
\text { (GSF) }\end{array}$ & 4.73E-03 & $1.95 \mathrm{E}-02$ \\
\hline & & $\begin{array}{l}\text { AR New Build Share } \\
\text { (NBS) }\end{array}$ & $9.50 \mathrm{E}-01$ & $9.80 \mathrm{E}-01$ \\
\hline & & $\begin{array}{l}\text { Reprocessing Start } \\
\text { Date (RPS) }\end{array}$ & $4.51 \mathrm{E}-03$ & $3.80 \mathrm{E}-03$ \\
\hline \multirow{4}{*}{$\begin{array}{c}\text { Mass of Waste } \\
\text { Disposed per Energy } \\
\text { Produced }\end{array}$} & \multirow{4}{*}{1.0} & $\begin{array}{l}\text { Reprocessing Capacity } \\
\text { (RPC) }\end{array}$ & 2.03E-01 & $2.33 \mathrm{E}-01$ \\
\hline & & $\begin{array}{l}\text { Energy Demand } \\
\text { Growth Scaling } \\
(\text { GSF })\end{array}$ & $-3.26 \mathrm{E}-03$ & $5.10 \mathrm{E}-03$ \\
\hline & & $\begin{array}{l}\text { AR New Build Share } \\
\text { (NBS) }\end{array}$ & 7.49E-01 & $7.48 \mathrm{E}-01$ \\
\hline & & $\begin{array}{l}\text { Reprocessing Start } \\
\text { Date (RPS) }\end{array}$ & $3.68 \mathrm{E}-03$ & $2.41 \mathrm{E}-03$ \\
\hline \multirow{4}{*}{$\begin{array}{l}\text { Levelized Cost of Fuel } \\
\text { Cycle Transition }\end{array}$} & \multirow{4}{*}{1.0} & $\begin{array}{l}\text { Reprocessing Capacity } \\
\text { (RPC) }\end{array}$ & $7.45 \mathrm{E}-03$ & $5.80 \mathrm{E}-02$ \\
\hline & & $\begin{array}{l}\text { Energy Demand } \\
\text { Growth Scaling } \\
\text { (GSF) }\end{array}$ & $7.62 \mathrm{E}-01$ & $8.27 \mathrm{E}-01$ \\
\hline & & $\begin{array}{l}\text { AR New Build Share } \\
\text { (NBS) }\end{array}$ & $1.57 \mathrm{E}-01$ & $2.47 \mathrm{E}-01$ \\
\hline & & $\begin{array}{l}\text { Reprocessing Start } \\
\text { Date (RPS) }\end{array}$ & $-7.79 \mathrm{E}-03$ & $1.31 \mathrm{E}-02$ \\
\hline
\end{tabular}

more expensive, but its construction costs are lower and fuel utilization is higher making its direct costs overall comparable for the timescale of the simulations but still higher. The main difference that drives this relationship is the cost of the associated facilities. For LWRs the cost of the increased natural uranium and enrichment capacity is directly tied to them, however, the cost of the reprocessing facilities and fuel fabrication facility is not directly tied to the deployment of advanced reactors and is instead set by the parameter RPC. This effectively decouples this cost from NBS.

The parameters and responses in this study were chosen to have predictable relationships in order to be able to judge the efficacy of the sensitivity analysis methods. As such, one or two parameters were intended to be the dominating contributors with little or no interaction for most responses. This is what is observed with an increase of fast reactors decreasing the natural uranium and reprocessing requirements and also decreasing the quantity of waste to be disposed all being indicated by NBS's high importance to those three metric. However, as indicated by the total effect index for GSF for natural uranium consumption and RPC for the cost of the fuel cycle transitions, there are synergistic effects. The presence of these synergies is indicated by the total effect index for the parameter being much larger than the main effect. Although the individual indices of each parameter do not directly indicate correlations between parameters, such synergistic effects can be inferred based on which parameters have a larger fraction of the sum of the total indexes relative to their fraction of the sum of the main indexes. In the case of natural uranium consumption, NBS is the only directly contributing parameter and no other parameter has a meaningful total index, making the relationship with GSF easy to 
infer. However, for the cost response metric, there are two directly contributing factors - NBS and GSF. Given that the total effect for both RPC and NBS are a greater fraction of the total effect index than they are for the main effects index, it can be inferred that the synergistic effect is dependent on these two parameters and not GSF. This effect is minor though, contributing approximately $5 \%$ of the total variance.

Similar to how unexpected relationships are revealed by the Sobol' indices, relationships that were expected based on prior experience were not exhibited. The most obvious of these is an expected synergistic relationship between reprocessing start date, reprocessing capacity, and levelized cost of the transition. It would be expected that starting a lower capacity reprocessing plant at an earlier date would result in less total capacity being required for the transition. Similar to how lower reprocessing capacity resulted in a lower mass of waste being disposed, it would also be expected that a later reprocessing start date would result in a lower mass of waste being disposed. These relationships not being reflected in the sensitivity analysis, together with the NBS relationship with cost and the RPC relationship with mass of waste disposed, further emphasizes potential shortcomings in the scenario or study as formulated, as the relationships do not reflect how the system would function in real-world application.

\section{Conclusions}

This study demonstrates some of the powerful analysis capabilities enabled through coupling the feature-rich design and analysis kit, Dakota, to the dynamic NFCS DYMOND. Through the development of this coupling, DYMOND can now be used to identify important design and policy parameters for transition scenarios and how those parameters interact not only with a single response, but also synergistically between all parameters and metrics of interest. This can also be done extremely rapidly with many variations with only a front-end computational expense by using previously generated scenarios to create surrogate models. Though only two surrogate model types and sensitivity analysis capabilities are demonstrated in this study, the coupling is equally functional for the machine learning surrogate model training and model optimization methods available in Dakota. The capabilities demonstrated, and the more advanced capabilities, are not limited to the parameters and responses outlined here. Any arbitrary parameters and responses can be analyzed through this coupling, with up to dozens of each being able to be accommodated in a single study. Furthermore, this capability allows for the analysis of the fuel cycle modeling capabilities and aids in identifying shortcomings or erroneous assumptions in the model or study. Due to the high level of variability and feedback mechanisms present in fuel cycle transition modeling, it is possible to make assumptions or formulate metrics that seem logical and plausible, even after single parametric studies are performed. However, multivariate and sensitivity analyses can help identify some of the shortcomings resulting from the approximations and assumptions adopted in these simulated scenarios that may not have been revealed otherwise.

This work was funded by the U.S. Department of Energy Office of Nuclear Energy's Systems Analysis \& Integration campaign. The authors also greatly appreciate the feedback on this work through collaborative interactions with Jin Whan Bae and Eva Davidson from Oak Ridge National Laboratory and Ross Hays from Idaho National Laboratory through the campaign's transition analysis activities. The submitted manuscript has been created by UChicago Argonne, LLC, Operator of Argonne National Laboratory ("Argonne"). Argonne, a U.S. Department of Energy Office of Science laboratory, is operated under Contract No. DE-AC02-06CH11357. The U.S. Government retains for itself, and others acting on its behalf, a paid-up nonexclusive, irrevocable worldwide license in said article to reproduce, prepare derivative works, distribute copies to the public, and perform publicly and display publicly, by or on behalf of the Government. The Department of Energy will provide public access to these results of federally sponsored research in accordance with the DOE Public Access Plan. http://energy.gov/downloads/ doe-public-access-plan.

\section{Author contribution statement}

S. Richards developed the presented capabilities, performed the accompanying study and analysis, and drafted the manuscript. B. Feng reviewed all results and the manuscript and also provided aid in the conceptualization of the study.

\section{References}

1. N. Thiollière, J. Clavel, F. Courtin, X. Doligez, M. Ernoult, Z. Issoufou, G. Krivtchik, B. Leniau, B. Mouginot, A. Bidaud, S. David, V. Lebrin, C. Perigois, Y. Richet, A. Somaini, A methodology for performing sensitivity analysis in dynamic fuel cycle simulation studies applied to a PWR fleet simulated with the CLASS tool, EPJ Nucl. Sci. Technol. 4, 13 (2018)

2. R. Wigeland, T. Taiwo, H. Ludewig, M. Todosow, W. Halsey, J. Gehin, R. Jubin, J. Buelt, S. Stockinger, K. Jenni, B. Oakley, Nuclear fuel cycle evaluation and screening final report, Fuel Cycle Research and Development D.O.E. Report FCRD-FCO-2014-000106 (2014)

3. U.S. Department of Energy, Advanced Fuel Cycle Cost Basis - 2017 Edition, NTRD-FCO-2017-000265 (2017)

4. H. Thierry, C. Senac, B. Feng, DYMOND 6 User Manual, (Argonne National Laboratory, 2019)

5. B.M. Adams, W.J. Bohnhoff, K.R. Dalbey, M.S. Ebeida, J.P. Eddy, M.S. Eldred, G. Geraci, R.W. Hooper, P.D. Hough, K.T. Hu, J.D. Jakeman, M. Khalil, K.A. Maupin, J.A. Monschke, E.M. Ridgway, A.A. Rushdi, J.A. Stephens, L.P. Swiler, D.M. Vigil, T.M. Wildey, J.G. Winokur, Dakota, A Multilevel Parallel Object-Oriented Framework for Design Optimization, Parameter Estimation, Uncertainty Quantification, and Sensitivity Analysis: Version 6.11 User's Manual, Sandia Technical Report SAND2014-4633, (July 2014; updated November 2019) 
6. Operating Nuclear Power Reactors, NRC.org, Nuclear Regulatory Commission (2020), www.nrc.gov/info-finder/ reactors

7. D.T. Ingersoll, Z.J. Houghton, R. Bromm, C. Desportes, NuScale small modular reactor for Co-generation of electricity and water, Desalination 340, 84-93 (2014)
8. T.K. Kim, W.S. Yang, C. Grandy, R.N. Hill, Core design studies for a 1000mwth advanced Burner reactor, Ann. Nucl. Energy 36, 331- 336 (2019)

9. N. Stauff, E. Hoffman, T. Kim, T. Taiwo, Unpublished Information (2015)

10. S. Kim, Private communication (2020)

Cite this article as: S. Richards and B. Feng, Application of Sensitivity Analysis in DYMOND/Dakota to Fuel Cycle Transition Scenarios, EPJ Nuclear Sci. Technol. 7, 26 (2021) 